\title{
Effect of Agomelatine in the Chronic Mild Stress Model of Depression in the Rat
}

\author{
Mariusz Papp*,', Piotr Gruca', Pierre-Alain Boyer ${ }^{2}$ and Elisabeth Mocaër ${ }^{2}$ \\ 'Institute of Pharmacology, Polish Academy of Sciences, Krakow, Poland; ${ }^{2}$ Institut de Recherches Internationales Servier, Courbevoie Cedex, \\ France
}

Chronic mild stress (CMS), a well-validated model of depression, was used to study the effects of the melatonin agonist and selective $5-\mathrm{HT}_{2 \mathrm{C}}$ antagonist agomelatine (S 20098) in comparison with melatonin, imipramine, and fluoxetine. All drugs were administered either $2 \mathrm{~h}$ before (evening treatment) or $2 \mathrm{~h}$ after (morning treatment) the dark phase of the 12 -h light/dark cycle. Chronic (5 weeks) evening treatment with agomelatine or melatonin (both at 10 and $50 \mathrm{mg} / \mathrm{kg}$ i.p.) dose-dependently reversed the CMS-induced reduction in sucrose consumption. The magnitude and time course of the action of both drugs was comparable to that of imipramine and fluoxetine (both at $10 \mathrm{mg} / \mathrm{kg}$ i.p.); however, melatonin was less active than agomelatine at this dose. The effect of evening administration of agomelatine and melatonin was completely inhibited by an acute injection of the $M T_{1} / M_{2}$ antagonist, S 22153 (20 mg/kg i.p.), while the antagonist had no effect in animals receiving fluoxetine or imipramine. When the drugs were administered in the morning, agomelatine caused effects similar to those observed after evening treatment (with onset of action faster than imipramine) but melatonin was ineffective. Moreover, melatonin antagonist, S 22153, did not modify the intakes in stressed animals receiving morning administration of agomelatine and in any other control and stressed groups tested in this study. These data demonstrate antidepressant-like activity of agomelatine in the rat CMS model of depression, which was independent of the time of drug administration. The efficacy of agomelatine is comparable to that of imipramine and fluoxetine, but greater than that of melatonin, which had no antidepressant-like activity after morning administration. While the evening efficacy of agomelatine can be related to its melatonin receptors agonistic properties, its morning activity, which was not inhibited by a melatonin antagonist, indicates that these receptors are certainly required, but not sufficient to sustain the agomelatine efficacy. It is therefore suggested that the antidepressant-like activity of agomelatine depends on some combination of its melatonin agonist and $5-\mathrm{HT}_{2} \mathrm{C}$ antagonist properties.

Neuropsychopharmacology (2003) 28, 694-703. doi:I 0. I038/s..npp. 130009 I

Keywords: antidepressant; agomelatine; melatonin; chronic mild stress; $5-\mathrm{HT}_{2} \mathrm{C}$ receptors; circadian; rat

\section{INTRODUCTION}

Agomelatine (S 20098; N(2-(7-methoxy-1-naphthyl)ethyl) acetamide) is a potent agonist of melatonin receptors (Yous et al, 1992; Ying et al, 1996; Conway et al, 2000) and an antagonist of the $5-\mathrm{HT}_{2 \mathrm{C}}$ receptor subtype (Cussac et al, 2002). Agomelatine shows a high affinity for cloned human receptors $\mathrm{MT}_{1}$ and $\mathrm{MT}_{2}$ subtypes $\left(K_{i}=6.15 \times 10^{-11}\right.$ and $2.68 \times 10^{-10} \mathrm{M}$, respectively) as well as for the $5-\mathrm{HT}_{2 \mathrm{C}}$ receptor $\left(\mathrm{IC}_{50}=2.7 \times 10^{-7} \mathrm{M}\right.$ on human cloned $5-\mathrm{HT}_{2 \mathrm{C}}$ receptors). The affinity of agomelatine at melatonin receptors is comparable to that of melatonin $\left(K_{i}=8.52 \times 10^{-11}\right.$ and $2.63 \times 10^{-10} \mathrm{M}$, respectively $)$ and, in line with this, agomelatine displaces iodomelatonin from its

* Correspondence: Dr M Papp, Institute of Pharmacology, Polish Academy of Sciences, 12 Smetna St., 3 I-343 Krakow, Poland, Tel: +48 I2 662 3352, Fax: +48 12637 4500, E-mail: nfpapp@cyf-kr.edu.pl Received 17 May 2002; revised 8 October 2002; accepted 14 October 2002

Online publication: 17 October 2002 at http: //www.acnp.org/citations/ Npp I01702410 binding sites in the suprachiasmatic nucleus (SCN) of the hypothalamus, the brain region involved in the mechanism of the endogenous biological clock (Bonnefond et al, 1993).

A number of studies have demonstrated chronobiotic activity of agomelatine. For example, this compound resets the electrical activity of the SCN (Ying et al, 1996) and resynchronizes experimentally disrupted circadian rhythms (Armstrong et al, 1993; Redman et al, 1995; Martinet et al, 1996; Van Reeth et al, 1997). After chronic administration, agomelatine dose-dependently restores the phase shifting response to a dark pulse (Van Reeth et al, 2001) and accelerates by $25 \%$ resynchronization of the rhythm to the new light-dark cycle in old hamsters (Weibel et al, 2000). The re-entraining activity of agomelatine, which is related to a direct effect on melatonin receptors in the SCN (Redman and Francis, 1998; Ying et al, 1998), is dosedependent, and shows a clear relation to plasma concentration of agomelatine (Martinet et al, 1996). The chronobiotic properties of agomelatine are of particular interest since the disorganization of internal rhythms is believed to be involved in the pathophysiology of depression (Wehr and 
Wirz-Justice, 1982). Indeed, positive responses to sleep deprivation and light therapies, as well as diurnal mood variations, indicate a dysfunction of circadian rhythms in depression (Healy, 1993). Moreover, depressed patients exhibit a blunting in the amplitude of their circadian rhythms, an abnormality that is no longer observed after their recovery following antidepressant therapy (Souetre et al, 1989). Depressed patients also present a phase advance of their circadian rhythms of melatonin relative to their sleep (Lewy et al, 1987; Sack et al, 1990; Dahl et al, 1993), along with cortisol and temperature rhythms.

In the present study, antidepressant-like activity of agomelatine was tested in the chronic mild stress (CMS) model, a chronic procedure based on the evaluation of anhedonia, that is, inability to experience pleasure, which is a core symptom of the human depressive disorder (see Willner, 1997). The CMS model appears to be particularly appropriate for studying antidepressant-like activity of compounds with chronobiotic properties since, apart from a deficit in their responsiveness to reward, animals exposed to the CMS procedure show advanced phase shift of diurnal rhythms (Gorka et al, 1996), diurnal variation with symptoms worst at the start of the dark (ie active) phase (D'Aquila et al, 1997), and a variety of sleep disorders characteristic of depression, including decreased rapid eye movement (REM) sleep latency, increased number of REM sleep episodes, and more fragmented sleep patterns (Moreau et al, 1995; Cheeta et al, 1997). All these findings indicate that the CMS procedure causes a generalized disorganization of internal rhythms, which are postulated to play an important role in the pathophysiology of depression (Wehr and Wirz-Justice, 1982).

In order to determine the involvement of circadian rhythms resynchronization in the action of agomelatine in the CMS model, this compound was administered at two time points: $2 \mathrm{~h}$ before (evening treatment) and $2 \mathrm{~h}$ after (morning treatment) the dark phase of the 12-h light/dark cycle, that is, when agomelatine is devoid of chronobiotic effect (Van Reeth et al, 1997). The effects of these treatments were compared with the results of similar administration of melatonin and traditional antidepressants, imipramine, and fluoxetine. Finally, the effect of an acute dose of S 22153, a melatonin receptor antagonist (Weibel et al, 1999), on the effects of all the above treatments was studied.

\section{MATERIAL AND METHODS}

\section{Animals}

Male Wistar rats ( $n=336$, Gorzkowska, Warsaw) were brought into the laboratory 2 months before the start of the experiment. Except as described below, the animals were singly housed with food and water freely available, and were maintained on a 12-h light/dark cycle (lights on at 08.00 ) at a temperature of $22 \pm 2{ }^{\circ} \mathrm{C}$. The study was conducted in compliance with the Animal Protection Bill of 21 August 1997, and has been approved by the Bioethical Committee at the Institute of Pharmacology, Polish Academy of Sciences, Krakow, Poland.

\section{Stress Procedure}

Animals were first trained to consume a $1 \%$ sucrose solution. Training consisted of ten 1-h baseline tests in which sucrose was presented, in the home cage, following $14 \mathrm{~h}$ of food and water deprivation. Sucrose intake was measured by weighing preweighed bottles containing the sucrose solution, at the end of the test. Subsequently, sucrose consumption was monitored, under similar conditions, at weekly intervals throughout the whole experiment. On the basis of their sucrose intake in the final baseline test, animals were divided into two matched groups. One group of animals was subjected to the chronic stress procedure for a period of 9 consecutive weeks. Each week of the stress regime consisted of: two periods of food or water deprivation; two periods of $45^{\circ}$ cage tilt; two periods of intermittent illumination (lights on and off every $2 \mathrm{~h}$ ); two periods of soiled cage ( $250 \mathrm{ml}$ water in sawdust bedding); two periods of paired housing; two periods of low intensity stroboscopic illumination (150 flashes/min); and two periods of no stress. All stressors were 10-14 h of duration and were applied individually and continuously, day and night. Control animals were housed in separate rooms and had no contact with the stressed animals. They were deprived of food and water for $14 \mathrm{~h}$ preceding each sucrose test, but otherwise food and water were freely available in the home cage.

\section{Drug Administration}

On the basis of their sucrose intake following initial 2 weeks of stress, both stressed and control animals were each further divided into matched subgroups $(n=8$ rats per group), and for subsequent 5 or 7 weeks (see below) they received daily intraperitoneal injections, either in the evening or in the morning.

Evening Administration. Vehicle (1\% hydroxy ethyl cellulose suspension in distilled water, $1 \mathrm{ml} / \mathrm{kg}$ ), agomelatine $(10$ and $50 \mathrm{mg} / \mathrm{kg}$ ), melatonin (10 and $50 \mathrm{mg} / \mathrm{kg}$ ), imipramine $(10 \mathrm{mg} / \mathrm{kg})$, or fluoxetine $(10 \mathrm{mg} / \mathrm{kg})$ were administered at $06.00 \mathrm{pm}$ (ie $2 \mathrm{~h}$ before the dark phase of the 12-h light/dark cycle) for 7 weeks. At Week 6, all animals received an acute dose of the melatonin antagonist, S 22153 (20 mg/kg, i.p.), 30 min before the sucrose test. After this test, treatments were continued and a final sucrose test was carried out at Week 7.

Morning Administration. Vehicle (1\% hydroxy ethyl cellulose suspension in distilled water, $1 \mathrm{ml} / \mathrm{kg}$ ) and agomelatine $(10$ and $50 \mathrm{mg} / \mathrm{kg})$ were administered at 10.00 am (ie $2 \mathrm{~h}$ after the dark phase of the 12-h light/dark cycle). After 5 weeks, all treatments were terminated and one additional sucrose test was carried out following 1 week of withdrawal. Other groups of animals received a similar administration of vehicle, agomelatine $(50 \mathrm{mg} / \mathrm{kg})$, melatonin $(50 \mathrm{mg} / \mathrm{kg})$, or imipramine $(10 \mathrm{mg} / \mathrm{kg})$ for 7 weeks. At Week 6 , these animals were injected $(30 \mathrm{~min}$ before the sucrose test) with an acute dose of the melatonin antagonist, S $22153(20 \mathrm{mg} / \mathrm{kg}$, i.p.). After this test, treatments were continued and a final sucrose test was carried out at Week 7. 


\section{Sucrose Tests}

The weekly sucrose tests were carried out $16 \mathrm{~h}$ (evening administration) or $24 \mathrm{~h}$ (morning administration) following the last drug injection. Stress was continued throughout the entire period of treatment and withdrawal.

\section{Statistics}

Changes in sucrose consumption during 5 weeks of vehicle and drug treatment in control and stressed animals were analyzed separately for morning and evening administration by multiple analysis of variance with group (stress/ control) and treatment (vehicle/drug) as the betweensubject factors and successive sucrose measurements (Weeks 0-5) as the within-subject factor. Effects of melatonin antagonist, S 22153, were analyzed by comparing sucrose consumption measured during three consecutive tests; that is, at Weeks 5, 6 (injection of S 22153), and 7. Similarly, separate analyses were performed for Weeks 5-6 to evaluate effects of withdrawal from agomelatine administration. The Fisher's LSD test was used for post hoc comparisons of means. $P$ values lower than 0.05 were considered statistically significant.

\section{Drugs}

Agomelatine (S 20098), S 22153 (N-[2-(5-ethylbenzo[b]thiophen-3yl)ethyl] acetamide, melatonin, and fluoxetine were provided by Servier (France), and imipramine was purchased from RBI (USA). All drugs were injected in a volume of $1 \mathrm{ml} / \mathrm{kg}$ body weight.

\section{RESULTS}

\section{Evening Administration}

CMS caused a gradual decrease in the consumption of $1 \%$ sucrose solution. Thus, in the final baseline test, all animals drank approximately 12-14 g of sucrose solution (data not shown) and following initial 2 weeks of stress (ie at Week 0 ), the intakes remained at the same level (approx. 13.5 g) in controls but fell to 8-8.5 $\mathrm{g}$ in stressed animals, resulting in a significant Group effect $(\mathrm{F}(1,104)=71.769 ; p<0.001)$. Such a difference between control and stressed animals treated with vehicle, persisted at similar level for the remainder of the 5-week treatment period, and was reflected in a significant Group effect $(\mathrm{F}(1,14)=8.844 ; p=0.01)$, and in the nonsignificant effects of Weeks and Group $\times$ Weeks interaction $(\mathrm{F}(5,70)=1.761$ and 1.395 , respectively) (see Figure 1). Acute injection of the melatonin antagonist, $S$ 22153, at Week 6 had no significant effect on sucrose intake in either control or stressed animals receiving vehicle (Group $\times$ Weeks interaction, $\mathrm{F}(2,28)=1.176$; NS) (see Figure 1 and Table 1).

Effects of imipramine and fluoxetine are presented in Figure 1 (upper panel). Chronic treatment with both drugs had no significant effect on sucrose intake in control animals and increased sucrose consumption in stressed animals, resulting in significant effects of Treatment (imipramine: $\mathrm{F}(1,28)=7.499 ; p<0.01$, fluoxetine: $\mathrm{F}(1,28)=$ 4.859; $p<0.05)$ and Treatment $\times$ Group $\times$ Weeks interac- tion (imipramine: $\mathrm{F}(4,112)=3.971 ; p<0.01$, fluoxetine: $\mathrm{F}(4,112)=3.452 ; p<0.01)$. As compared to Week 0 scores, the increases in sucrose intake in stressed animals administered with imipramine and fluoxetine reached statistical significance after 3 weeks of treatment. This effect was maintained and further enhanced thereafter, and at Week 5 the amount of sucrose solution drunk by these animals was comparable to that of vehicle-treated controls (imipramine: $p=0.067$, fluoxetine: $p=0.329$ ) and significantly higher than that of vehicle-treated stressed animals (imipramine: $p=0.0005$, fluoxetine: $p=0.006$ ). The sucrose consumption in control and stressed animals receiving imipramine and fluoxetine was not affected by acute injection of the melatonin antagonist, S 22153, as evidenced by nonsignificant Group $\times$ Weeks interaction effects for imipramine and fluoxetine $(\mathrm{F}(2,28)=0.214$ and 0.229 , respectively; see Figure 1, upper panel).

Effects of agomelatine. As shown in Figure 2 (upper panel), evening administration of agomelatine did not affect the consumption of sucrose solution in control animals $(\mathrm{F}(2,21)=0.158$; NS) but in stressed animals agomelatine caused a significant Treatment effect $(\mathrm{F}(2,21)=4.809$; $p<0.05)$. In consequence, when compared to vehicle injections, the overall effect of 5 weeks of agomelatine treatment led to significant effects of Group $(\mathrm{F}(1,42)=$ $12.855 ; p<0.001)$, Weeks $(\mathrm{F}(5,210)=4.414 ; p<0.001)$ and interaction $(\mathrm{F}(10,210)=3.585 ; p<0.01)$. The increase in sucrose consumption was apparent during the first 3 weeks of treatment, and reached statistical significance at Week 4 in stressed animals receiving the higher dose of $50 \mathrm{mg} / \mathrm{kg}$ $(p<0.05)$ and at Week 5 in animals treated with the lower dose of $10 \mathrm{mg} / \mathrm{kg}(p<0.01)$.

Acute injection of the melatonin antagonist, S 22153, was without any effect in control animals treated with both doses of agomelatine, but it completely reversed recovery of sucrose drinking in stressed animals (Weeks effect: $\mathrm{F}(2,56)=4.413 ; p<0.001$ and Weeks $\times$ Group interaction: $\mathrm{F}(2,28)=4.726 ; p<0.05)$ (see Table 1$)$. In stressed animals treated with $50 \mathrm{mg} / \mathrm{kg}$ of agomelatine, this inhibition disappeared in the following week (Week 7) and their intakes were again comparable to that of vehicle-treated controls $(p=0.839)$ and significantly higher than that of vehicle-treated stressed animals $(p=0.001)$. Animals receiving a lower dose of $10 \mathrm{mg} / \mathrm{kg}$ also drank more sucrose solution on the following test, but this effect was not significant $(p=0.171)$ and the intakes in these animals at Week 7 were just above that seen in the vehicle-treated stressed group (see Table 1).

Effects of melatonin. As shown in Figure 2 (lower panel), evening treatment with melatonin did not significantly affect the consumption of sucrose solution in controls, but gradually increased sucrose drinking in stressed animals, resulting in significant effects of Group $(\mathrm{F}(1,42)=18.474$; $p<0.001)$, Weeks $(\mathrm{F}(5,210)=11.063 ; p<0.001)$, and interaction $(\mathrm{F}(10,210)=3.291 ; p<0.01)$. When compared to Week 0 values, the increase of sucrose drinking in animals receiving the highest dose of $50 \mathrm{mg} / \mathrm{kg}$ reached statistical significance after 3 weeks of treatment $(p=0.001)$. This effect was further enhanced and, after 5 weeks of treatment, the intakes in these animals did not differ from those 

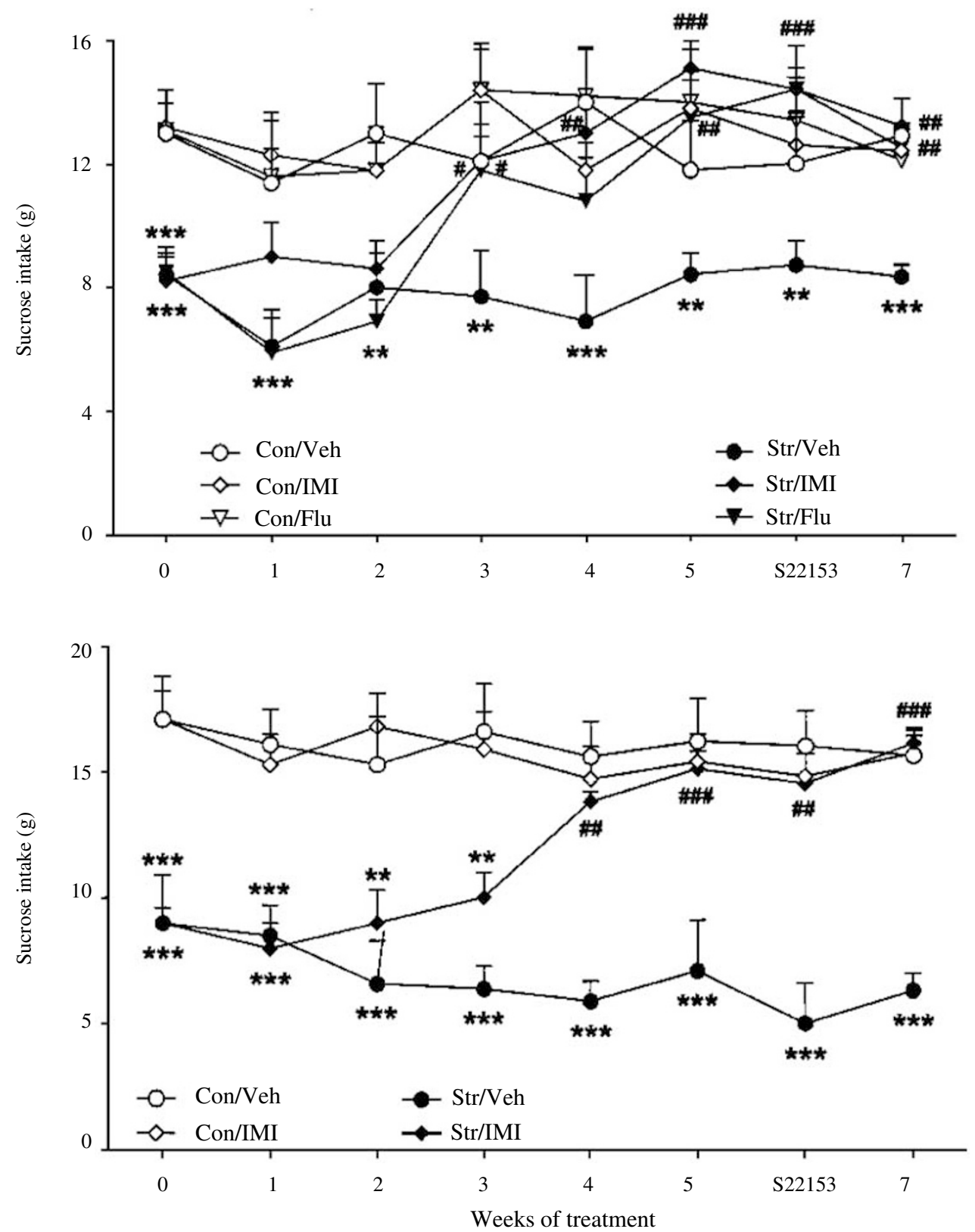

Figure I Consumption of $1 \%$ sucrose solution, in controls (Con, open symbols) and in animals exposed to CMS (Str, closed symbols). Upper panel shows effects of vehicle (I ml/ $\mathrm{kg}$ ), imipramine, and fluoxetine (both at $10 \mathrm{mg} / \mathrm{kg}$ ) administered at $06.00 \mathrm{pm}$, that is, $2 \mathrm{~h}$ before the dark phase of the 12 -h light/ dark cycle (evening administration). Lower panel shows effects of vehicle $(1 \mathrm{ml} / \mathrm{kg})$ and imipramine $(10 \mathrm{mg} / \mathrm{kg})$ administered at 10.00 am, that is, $2 \mathrm{~h}$ after the dark phase of the 12-h light/dark cycle (morning administration). At Week 6, all animals were injected with $20 \mathrm{mg} / \mathrm{kg}$ of melatonin antagonist, S 22 I 53 (see text for details). Values are means \pm SEM. ${ }^{* *} p<0.0$ I, ${ }^{* * * *} p<0.00$ I; relative to vehicle- or drug-treated control animals. ${ }^{\#} p<0.05,{ }^{\# \#} p<0.01$, ${ }^{\# \# \#} p<0.00$ I; relative to drug-treated stressed animals at Week 0 .

measured in vehicle-treated controls $(p=0.223)$ and were significantly higher than those of vehicle-treated stressed animals $(p<0.005)$. The action of the lower dose of $10 \mathrm{mg} /$ $\mathrm{kg}$ was slower; the increase of sucrose consumption was significant only after 5 weeks of treatment $(p<0.05)$ and, at this point, the intakes in stressed animals receiving $10 \mathrm{mg} /$ $\mathrm{kg}$ of melatonin were midway between those seen in both the drug- and vehicle-treated control and stressed groups (see Figure 2, lower panel). Melatonin antagonist, S 22153, administered acutely prior to the sucrose test at Week 6, completely reversed the effects of melatonin in the CMS model-the sucrose consumption in both melatonintreated stressed groups returned to the level of vehicle- treated stressed animals (Weeks effect: $\mathrm{F}(2,56)=6.348$; $p<0.01$ ) (see Table 1). This inhibitory action of S 22153 was short lasting; in the following test at Week 7, full recovery of sucrose drinking was again apparent in animals receiving a higher dose of $50 \mathrm{mg} / \mathrm{kg}$ of melatonin. Animals administered $10 \mathrm{mg} / \mathrm{kg}$ also increased their intakes, relative to Week 6 , but this effect was not significant $(p=0.243)$.

Table 2 shows that at the end of the treatment period the vehicle-treated control animals were smaller than the stressed animals but this difference was not significant (Group effect: $\mathrm{F}(1,14)=1.238$; NS). As compared to vehicletreated groups, body weights of control and stressed animals were not significantly affected by imipramine 
Table I Sucrose Consumption in Control (Con) and Stressed (Str) Animals in Three Consecutive Tests

\begin{tabular}{lrrr}
\hline & Week 5 & $\begin{array}{c}\text { Week 6 } \\
\text { (S 22 153) }\end{array}$ & Week 7 \\
\hline Evening administration & & & \\
Con/Veh & $11.8 \pm 1.6$ & $12.0 \pm 1.5$ & $12.9 \pm 1.2$ \\
Str/Veh & $8.4 \pm 0.7$ & $8.7 \pm 0.8$ & $8.3 \pm 0.4$ \\
Con/agomelatine, $10 \mathrm{mg}$ & $13.1 \pm 1.8$ & $11.2 \pm 1.1$ & $11.6 \pm 1.9$ \\
Str/agomelatine, $10 \mathrm{mg}$ & $13.7 \pm 1.7$ & $7.0 \pm 1.3 *$ & $9.1 \pm 1.3$ \\
Con/agomelatine, $50 \mathrm{mg}$ & $13.6 \pm 1.8$ & $12.1 \pm 1.4$ & $14.6 \pm 1.3$ \\
Str/agomelatine, $50 \mathrm{mg}$ & $14.5 \pm 1.1$ & $8.8 \pm 1.4 *$ & $13.3 \pm 1.0 * * *$ \\
Con/melatonin, $10 \mathrm{mg}$ & $14.5 \pm 1.4$ & $13.7 \pm 1.3$ & $13.4 \pm 1.5$ \\
Str/melatonin, $10 \mathrm{mg}$ & $11.5 \pm 0.8$ & $8.8 \pm 0.9$ & $10.0 \pm 0.8$ \\
Con/melatonin, $50 \mathrm{mg}$ & $13.5 \pm 0.9$ & $14.1 \pm 1.2$ & $13.7 \pm 1.0$ \\
Str/melatonin, $50 \mathrm{mg}$ & $13.8 \pm 1.1$ & $8.9 \pm 1.2$ & $12.4 \pm 0.9$ \\
& & & \\
Morning administration & & & \\
Con/Veh & $16.2 \pm 1.7$ & $16.0 \pm 1.4$ & $15.6 \pm 1.1$ \\
Str/Veh & $7.1 \pm 2.0$ & $5.0 \pm 1.6$ & $6.3 \pm 0.7$ \\
Con/agomelatine, $50 \mathrm{mg}$ & $16.0 \pm 1.4$ & $14.1 \pm 0.8$ & $13.9 \pm 0.9$ \\
Str/agomelatine, $50 \mathrm{mg}$ & $15.7 \pm 0.8$ & $14.1 \pm 0.6$ & $15.7 \pm 0.8$ \\
Con/melatonin, $50 \mathrm{mg}$ & $16.3 \pm 1.2$ & $14.5 \pm 0.9$ & $15.4 \pm 0.8$ \\
Str/melatonin, $50 \mathrm{mg}$ & $6.1 \pm 1.4$ & $7.6 \pm 1.4$ & $6.3 \pm 1.2$ \\
\hline
\end{tabular}

At Week 6 all animals received an acute injection of the melatonin antagonist, S $22153(20 \mathrm{mg} / \mathrm{kg}$, see text for details). Values are means \pm SEM. $* 2<0.00$ I, relative to Week 5 values; ${ }^{*} * x<0.00$ I, relative to Week 6 values

(controls: $\mathrm{F}(1,14)=0.055 ;$ stressed: $\mathrm{F}(1,14)=0.099 ; \quad \mathrm{NS}$ ) while fluoxetine caused significant effect in control $(\mathrm{F}(1,14)=8.947 ; p<0.01)$, but not in stressed animals $(\mathrm{F}(1,14)=0.030$; NS). Chronic treatment with melatonin had no significant effect on body weights of both control $(\mathrm{F}(2,21)=1.064 ; \mathrm{NS})$ and stressed $(\mathrm{F}(2,21)=0.174 ; \mathrm{NS})$ animals. The effect of chronic administration of agomelatine on body weights was also not significant (controls: $\mathrm{F}(2,21)=0.899$; NS, stressed: $\mathrm{F}(2,21)=0.747)$.

\section{Morning Administration}

In the final baseline test, all animals drank approximately $14-16 \mathrm{~g}$ of the solution (data not shown) and following initial 2 weeks of stress (ie at Week 0), intakes remained at similar level in controls but fell to approximately $7-9 \mathrm{~g}$ in stressed animals (Group effect: $\mathrm{F}(1,56)=79.646 ; p<0.001$ ). Such a difference between control and stressed animals treated with vehicle persisted at a similar level until the end of the 5-week treatment period, resulting in a significant Group effect $(\mathrm{F}(1,14)=26.459 ; p<0.001)$ and nonsignificant effects of Weeks and Group $\times$ Weeks interaction $(\mathrm{F}(5,70)=1.159$ and 0.383 , respectively; see Figure 1). Acute injection of melatonin antagonist, S 22153, at Week 6 did not affect sucrose intake in both control and stressed animals receiving vehicle (Group $\times$ Weeks interaction: $\mathrm{F}(2,28)=0.354$; NS) (see Figure 1 and Table 1).

Effects of imipramine. As shown in Figure 1 (lower panel), chronic treatment with imipramine had no significant effect on sucrose intake in control animals and increased sucrose consumption in stressed animals, resulting in a significant Treatment effect $(\mathrm{F}(128)=4.301 ; p<0.05)$ and Treatment $\times$ Group $\times$ Weeks interaction $\quad(F(5,140)=4.677$; $p<0.001)$. As compared to Week 0 scores, the increases in sucrose intake in stressed animals receiving morning administration of imipramine reached statistical significance after 3 weeks of treatment $(p<0.01)$ and this effect was further enhanced and maintained thereafter. The sucrose consumption in control and stressed animals treated with imipramine was not affected by S 22153 (Group $\times$ Weeks interaction: $\mathrm{F}(2,28)=0.162 ; \mathrm{NS}) \quad$ (see Figure 1, lower panel).

Effects of agomelatine are shown in Figure 3. Morning administration of agomelatine had no significant effect on sucrose intake in control animals $(\mathrm{F}(2,21)=0.204$; NS) while in stressed animals it caused a highly significant Treatment effect $(\mathrm{F}(2,21)=12.133 ; p<0.001$, Figure 3 , upper panel). In consequence, when compared to vehicle injections, the overall effect of 5 weeks of agomelatine treatment resulted in significant effects of Group $(\mathrm{F}(1,42)=22.404 ; \quad p<0.001), \quad$ Weeks $\quad(\mathrm{F}(5,210)=3.856$; $p<0.01)$ and interaction $(\mathrm{F}(10,210)=2.512 ; p<0.01)$. The action of agomelatine was dose-dependent; increases in sucrose intake reached first statistical significance after 3 weeks of treatment with the lower dose of $10 \mathrm{mg} / \mathrm{kg}$ $(p<0.05)$ and already after the first week of treatment with a higher dose of $50 \mathrm{mg} / \mathrm{kg} \quad(p<0.05)$. This effect was maintained or enhanced thereafter and at Week 5 the sucrose intakes in stressed animals receiving the two doses of agomelatine were comparable to those measured in the drug- and vehicle-treated control groups (see Figure 3, upper panel). At 1 week after cessation of treatment, the intakes remained at similar levels in both control and stressed animals (Week 5 vs Withdrawal: Group, Weeks, and interaction effects $(\mathrm{F}(1,28)=0.63,1.041$, and 1.502, respectively; all nonsignificant, see Figure 3, upper panel).

Effects of melatonin. As shown in the lower panel of Figure 3 , morning administration of melatonin for 5 weeks did not change sucrose intake in either control or stressed animals, resulting in a significant Group effect $(F(1,28)=86.406$; $p<0.001)$ and nonsignificant effects of Treatment $(\mathrm{F}(1,28)=0.077)$, Weeks $(\mathrm{F}(5,140)=2.139)$, and interaction $(\mathrm{F}(5,140)=0.250)$. Acute injection of S 22153 at Week 6 was without any effect on the sucrose consumption in both control and stressed animals treated with melatonin $(\mathrm{F}(2,28)=0.059$; NS, see Table 1$)$. Importantly, this experiment also included control and stressed animals administered $50 \mathrm{mg} / \mathrm{kg}$ of agomelatine and the results were comparable to those described in previous paragraph - no effect in control animals and fast (ie following first 2 weeks of treatment) recovery from the CMS-induced deficit in sucrose consumption (see Figure 3, lower panel). As shown in Table 1, sucrose drinking in both control and stressed animals receiving $50 \mathrm{mg} / \mathrm{kg}$ of agomelatine in the morning was not affected by acute injection of the melatonin antagonist, S 22153 (Weeks effects: $\mathrm{F}(2,28)=2.068$; NS, Weeks $\times$ Group interaction: $F(2,28)=2.119$; NS).

At the end of the treatment period, vehicle-treated stressed animals were smaller than controls, but this difference did not reach statistical significance (Group effect: $\mathrm{F}(1,14)=1.127$; NS). As compared to vehicle-treated groups, the body weights of control and stressed animals were not significantly affected by imipramine (controls: $\mathrm{F}(1,14)=0.197$; NS, stressed: $\mathrm{F}(1,14)=0.1 .172 ; \mathrm{NS})$, melatonin 
Evening administration
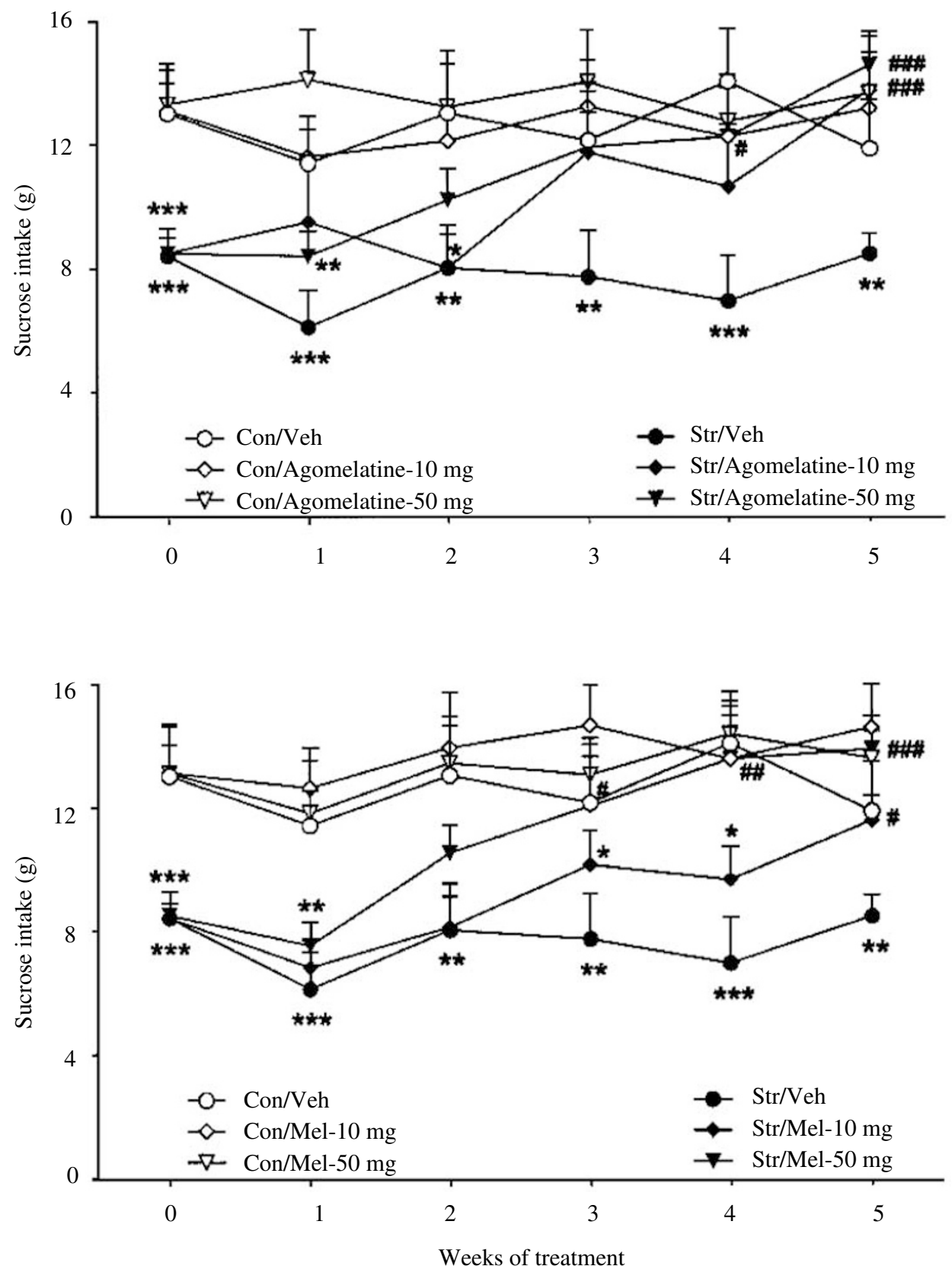

Figure 2 Effects of evening administration of vehicle ( $1 \mathrm{ml} / \mathrm{kg}$ ), agomelatine, and melatonin (both at 10 and $50 \mathrm{mg} / \mathrm{kg}$, i.p.) on the consumption of $1 \%$ sucrose solution, in controls (Con, open symbols) and in animals exposed to CMS (Str, closed symbols). All drugs were administered at $06.00 \mathrm{pm}$, that is, $2 \mathrm{~h}$ before the dark phase of the I2-h light/dark cycle. Values are means \pm SEM. $* p<0.05, * * p<0.01$, *** $p<0.001$; relative to vehicle- or drug-treated control

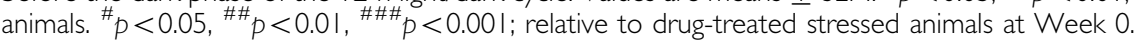

(control: $\mathrm{F}(1,14)=1.595 ; \mathrm{NS}$, stressed: $\mathrm{F}(1,14)=0.014 ; \mathrm{NS})$, or agomelatine (controls: $\mathrm{F}(1,14)=0.504$; NS, stressed: $\mathrm{F}(1,14)=0.002$; NS, data not shown).

\section{DISCUSSION}

The results of this study confirm earlier reports that chronic sequential exposure to a variety of mild stressors causes a substantial decrease in the consumption of $1 \%$ sucrose solution, and that this deficit can be effectively reversed by chronic treatment with traditional antidepressant drugs, imipramine, and fluoxetine (Muscat et al, 1992). Moreover, as in most of the previous studies with the CMS model (see Willner, 1997), also in this study the action of both antidepressants had several parallels with that of their clinical activity, both in terms of their efficacy (full recovery at the end treatment period), specificity (lack of significant 
Table 2 Body Weights (g) Measured at the End of Drugs Administration

\begin{tabular}{lll}
\hline Groups & Controls & Stressed \\
\hline Vehicle & $446 \pm 10$ & $421 \pm 19$ \\
Imipramine & $440 \pm 21$ & $429 \pm 13$ \\
Fluoxetine & $401 \pm 10 *$ & $417 \pm 15$ \\
Agomelatine & & \\
$10 \mathrm{mg} / \mathrm{kg}$ & $471 \pm 13$ & $438 \pm 6$ \\
$50 \mathrm{mg} / \mathrm{kg}$ & $455 \pm 16$ & $417 \pm 7$ \\
Melatonin & & \\
$10 \mathrm{mg} / \mathrm{kg}$ & $438 \pm 15$ & $406 \pm 17$ \\
$50 \mathrm{mg} / \mathrm{kg}$ & $415 \pm 19$ & $420 \pm 23$ \\
\hline
\end{tabular}

* $p<0.05$; relative to vehicle-treated control animals. effects in control animals), and time course (4-5 weeks of treatment required to reverse the deficit in sucrose consumption).

However, the main finding of the present study is that the CMS-induced reduction in the intake of sweet solution can be normalized by chronic administration of agomelatine ( $S$ 20098), a potent agonist of melatonin $\mathrm{MT}_{1}$ and $\mathrm{MT}_{2}$ receptors (Yous et al, 1992; Ying et al, 1996; Conway et al, 2000 ) and an antagonist of the $5-\mathrm{HT}_{2 \mathrm{C}}$ receptors (Cussac et al, 2002).

As mentioned earlier (see Introduction), among other biochemical, physiological and behavioral impairments, the CMS procedure causes generalized disorganization of
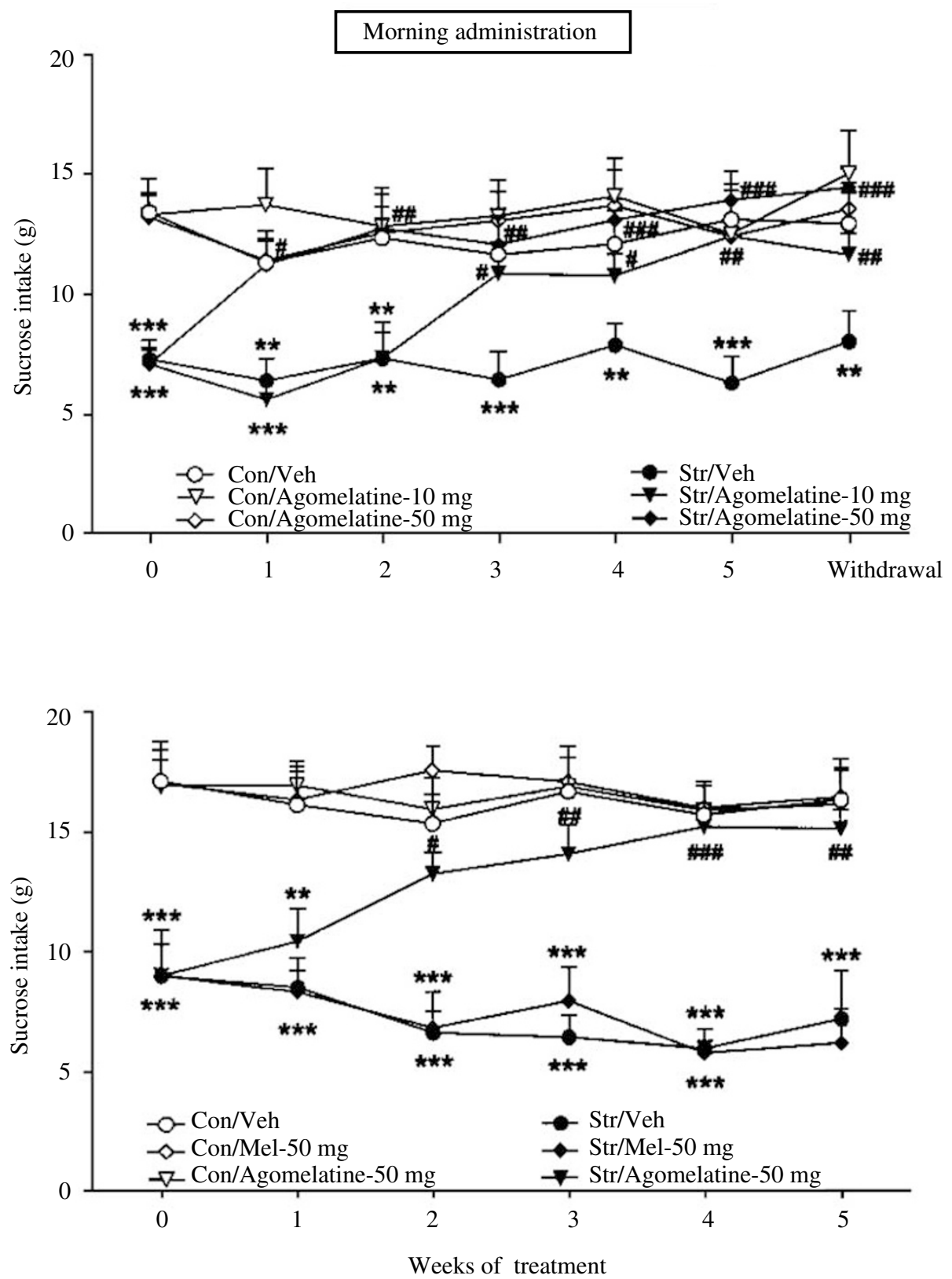

Figure 3 Effects of morning administration of vehicle $(\mathrm{I} \mathrm{ml} / \mathrm{kg})$, agomelatine $(10$ and $50 \mathrm{mg} / \mathrm{kg})$, and melatonin $(50 \mathrm{mg} / \mathrm{kg})$ on the consumption of $1 \%$ sucrose solution in controls (Con, open symbols) and in animals exposed to CMS (Str, closed symbols). All drugs were administered at I0.00 am, that is, $2 \mathrm{~h}$ after the dark phase of the 12-h light/dark cycle. Values are means \pm SEM. $* * *<0.01$, $* * * * p<0.001$; relative to vehicle- or drug-treated control animals. ${ }^{\#} p<0.05,{ }^{\# \#} p<0.01,{ }^{\# \# \#} p<0.001$; relative to drug-treated stressed animals at Week 0 . 
circadian rhythms, and agomelatine can resynchronize experimentally disrupted circadian rhythms. Therefore, in order to verify the hypothesis that antidepressant-like action of agomelatine in the CMS model involves its chronobiotic properties, the chronic injection of this compound was performed either in the evening, that is, when it shows most potent chronobiotic activity, or in the morning, that is, when agomelatine is clearly devoid of such an activity (Van Reeth et al, 1997). The results obtained in this study demonstrate that similar efficacy of agomelatine in the CMS model can be observed independent of the time of administration. In other words, both morning and evening administration of agomelatine resulted in a full and dose-dependent reversal of the CMS-induced deficit in sucrose consumption, without any significant effects in nonstressed control animals. The magnitude of this action of agomelatine was comparable to that of fluoxetine and imipramine but the onset of action, in particular when the compound was administered in the morning, was faster than that usually observed following chronic administration of traditional antidepressants as the intakes in stressed animals receiving agomelatine was apparent within the first 2 weeks of treatment, compared to 4 weeks required by imipramine. Although in this study fluoxetine was not included in the 'morning' experiment, in many of our previous studies this drug was administered at similar time and the onset of its action was comparable (ie 3-4 weeks delay) to that reported here for imipramine (Papp and Sánchez, 2002; Papp, unpublished data).

In contrast, melatonin, which was tested in parallel with agomelatine, was effective against the CMS-induced decrease of sucrose intakes only when administered $2 \mathrm{~h}$ before the dark phase of the 12-h light/dark cycle, melatonin being less active than agomelatine at the dose of $10 \mathrm{mg} / \mathrm{kg}$ - the morning injections of melatonin failed to affect the intakes in both the stressed and control animals. These results suggest that the antidepressant-like action of agomelatine in the CMS model involves two different mechanisms, which depend on the time of its administration. The effect of evening treatment can be related to the agonistic action on melatonin receptors, which in consequence leads to normalization of the general impairment of circadian rhythms previously observed in animals undergoing the CMS procedure (Moreau et al, 1995; Gorka et al, 1996; Cheeta et al, 1997; D'Aquila et al, 1997). Actually, contrary to the dose-dependent morning activity of agomelatine, the ceiling effect observed after evening administration can be related to its chronobiotic activity, which is maximal at 8$10 \mathrm{mg} / \mathrm{kg}$ (Redman et al, 1995; Martinet et al, 1996). This possibility is strongly supported by the finding that the melatonin antagonist, S 22153, given acutely to stressed animals successfully treated with agomelatine and melatonin, fully reversed the effectiveness of both agents. Interestingly, this inhibitory effect of S 22153 was transient in that it was no longer seen in the sucrose test carried out on the following week, and was not observed in any other control and stressed animals tested in this study, including those treated with imipramine and fluoxetine. These data indicate that the mechanism of therapeutic action of evening administration of agomelatine and melatonin in the CMS model of depression differs from that of traditional antidepressants, and provides further evidence that the antidepressant-like effect of agomelatine depends, at least partially, on its chronobiotic properties exerted by an interaction with melatonin receptors. This conclusion is consistent with other reports showing that agomelatine can resynchronize circadian rhythms in animals (Armstrong et al, 1993; Redman et al, 1995; Martinet et al, 1996; Van Reeth et al, 1997, 2001; Weibel et al, 2000) and with known clinical observations that disorganization of internal rhythms is one of the most characteristic feature of various depressive disorders and diurnal mood variations (Souetre et al, 1989; Wehr and Wirz-Justice, 1982; Healy, 1993).

Similar action of agomelatine and melatonin in the CMS model and inhibition of this effect by the melatonin antagonist, S 22153 (inactive in the CMS model when given alone - data not shown), strongly indicate the involvement of melatonin receptors in antidepressant-like action of evening administration of agomelatine and confirms other preclinical reports that melatonin can be effective as an antidepressant. For example, melatonin can prevent some of the behavioral disturbances produced by the CMS procedure in $\mathrm{C} 3 \mathrm{H} / \mathrm{He}$ mice, but with lower efficacy than fluoxetine (Kopp et al, 1999). Antidepressant-like effects of melatonin have also been reported in the forced swim test (Overstreet et al, 1998; Shaji and Kulkarni, 1998; Raghavendra et al, 2000). The clinical studies with melatonin and depression are less clear as, for example, both decreases (Beck-Friis et al, 1985; Brown et al, 1985; Zetin et al, 1987) as well as increases (Claustrat et al, 1984; Thompson et al, 1988; Sekula et al, 1997) in melatonin secretion have been reported in patients with diagnosis of major depression. Moreover, although a relation between melatonin levels and depression has been reported by Souetre et al (1989), this has not been confirmed by other authors (Beck-Friis et al, 1995; Rubin et al, 1992; Szymanska et al, 2001).

As there is no demonstration in the literature that a pure melatonin agonist activity can lead to antidepressant activity similar to that of agomelatine, it seems probable that receptors other than $\mathrm{MT}_{1}$ and $\mathrm{MT}_{2}$ are implicated in the mechanism of action of agomelatine. Actually, as shown in Figure 3, agomelatine was also effective against the CMSinduced deficit in sucrose consumption when administered in the morning. At this point of the circadian rhythm agomelatine is devoid of chronobiotic activity (Van Reeth et al, 1997) and its action in the CMS model was not affected by an acute injection of the melatonin antagonist. This suggests that the morning antidepressant-like action of agomelatine does not depend on its agonism at melatonin receptors. This conclusion is further reinforced by the fact that, in contrast to its evening efficacy, the morning treatment with melatonin was ineffective against the CMSinduced anhedonia, and, consistently, the melatonin antagonist had no effect on the behavior of stressed animals receiving either melatonin or agomelatine at this time of day.

As mentioned earlier, apart from its agonistic properties at melatonin $\mathrm{MT}_{1}$ and $\mathrm{MT}_{2}$ receptors (Yous et al, 1992; Ying et al, 1996; Conway et al, 2000), agomelatine has also a potent antagonistic activity at $5-\mathrm{HT}_{2 \mathrm{C}}$ receptors (Cussac et al, 2002) and numerous findings indicate that reduced function of $5-\mathrm{HT}_{2 \mathrm{C}}$ receptors may be involved in the mechanism by which antidepressants alleviate depression (see Sanchez and Hyttel, 1999). Moreover, the unselective 
$5-\mathrm{HT}_{2}$ antagonist mianserin is an effective antidepressant (Brogden et al, 1978; Montgomery, 1980; De Ridder, 1982), and efficacy of the $5-\mathrm{HT}_{2 \mathrm{~A} / 2 \mathrm{C}}$ antagonist ritanserin has also been shown in some clinical trials (Strauss and Klieser, 1991). Interestingly, some of these antidepressants, which are antagonists at $5-\mathrm{HT}_{2 \mathrm{C}}$ receptors (including imipramine, fluoxetine, maprotiline, amitriptyline, desipramine, and mianserin), have been shown to be effective in the CMS model (see Willner, 1997). In view of these data, it can be speculated that the effect of morning administration of agomelatine in the CMS model involves its interaction with $5-\mathrm{HT}_{2 \mathrm{C}}$ receptors.

It should be noted that dose ranges for chronobiotic activity of agomelatine in rats and other rodents are between 2.5 and $20 \mathrm{mg} / \mathrm{kg}$ (Martinet et al, 1996), while its antidepressant-like effects are observed at doses of 10 and $50 \mathrm{mg} / \mathrm{kg}$. At these doses, agomelatine has the most potent antagonist properties at $5-\mathrm{HT}_{2 \mathrm{C}}$ receptors (Cussac et al, 2002). These data suggest that chronobiotic effect alone is certainly required but not sufficient to get an antidepressant activity, and together with the results of the present study, they provide additional support for the hypothesis that antidepressant activity of S 20098 may require a combined action at both the melatonin and $5-\mathrm{HT}_{2 \mathrm{C}}$ receptors.

In conclusion, the present studies demonstrate antidepressant-like activity of agomelatine (S 20098), which is independent of the time of administration and appears to involve a combination of agonism at melatonin $\mathrm{MT}_{1}$ and $\mathrm{MT}_{2}$ and antagonism at $5-\mathrm{HT}_{2 \mathrm{C}}$ receptors.

\section{ACKNOWLEDGEMENTS}

The excellent technical assistance of E Moryl and Z Galoch is greatly appreciated.

\section{REFERENCES}

Armstrong SM, Mcnulty OM, Guardiola-Lemaître B, Redman JR (1993). Successful use of S 20098 and melatonin in an animal model of delayed sleep-phase syndrome. Pharmacol Biochem Behav 46: 45-49.

Beck-Friis J, Ljunggren JG, Thorsen M, Van Rosen JG, Kjellman BK, Wetterberg L (1985). Melatonin, cortisol and ACTH in patients with major depressive disorder and healthy humans with special reference to the outcome of the dexamethasone suppression test. Psychoneuroendocrinology 10: 173-186.

Bonnefond C, Martinet L, Lesieur D, Adam G, Guardiola-Lemaittre B (1993). Characterization of S-20098, a new melatonin analogue. In: Touitou Y, Arendt J, Pevet P (eds). Melatonin and the Pineal Gland. Elsevier Science Publishers: Amsterdam. pp 123-126.

Brogden RN, Heel RC, Speight TM, Avery GS (1978). Mianserin: a review of its pharmacological properties and therapeutic efficacy in depressive illness. Drugs 16: 273-301.

Brown RP, Koccis JH, Caroff S, Amsterdam J, Winokar A, Stekes P (1985). Difference in nocturnal melatonin secretion between melancholic depressed patients and control subjects. Am J Psychiatry 142: 811-816.

Cheeta S, Ruigt G, van Proosdij J, Willner P (1997). Changes in sleep architecture following chronic mild stress. Biol Psychiatry 41: 419-427.

Claustrat B, Chazot G, Brun J, Jordan D, Sassolas G (1984). A chronobiological study of melatonin and cortisol secretion in depressed subjects: plasma melatonin, a biological marker in major depression. Biol Psychiatry 19: 1215-1228.

Conway S, Canning SJ, Edward Howell HH, Mowat ES, Barrett P, Drew JE et al (2000). Characterizations of human $\mathrm{mt} 1 / \mathrm{MT}_{2}$ receptors by CRE-luciferase reporter assay. Eur J Pharmacol 390: $15-24$.

Cussac D, Newman-Tancredi A, Pasteau V, Millan MJ (2002). Antagonist properties of the melatonin agonist S 20098 (agomelatine) at recombinant, human (h) serotonin (5-HT2c), receptors. Int J Neuropsychopharmacol 5(Suppl 1): S68.

Dahl K, Avery DH, Lewy AJ, Savage MV, Brengelmann GL, Larsen $\mathrm{L}$ et al (1993). Dim light melatonin onset and circadian temperature during a constant routine in hypersomnic winter depression. Acta Psychiatr Scand 88: 60-66.

D’Aquila P, Newton J, Willner P (1997). Diurnal variation in the effect of chronic mild stress on sucrose intake and preference. Physiol Behav 62: 421-426.

De Ridder JJ (1982). Mianserin: a result of a decade of antidepressant research. Pharm Weekbl Sci 22: 139-145.

Gorka Z, Moryl E, Papp M (1996). Effect of chronic mild stress on circadian rhythms in the locomotor activity in rats. Pharmacol Biochem Behav 54: 229-234.

Healy D (1993). Dysphoria. In: Costelloe G (ed). The Symptoms of Depression. Wiley and Sons: Chichester. pp 24-45.

Kopp C, Vogel E, Rettori MC, Delagrange P, Misslin R (1999). The effects of melatonin on the behavioural disturbances induced by chronic mild stress in $\mathrm{C} 3 \mathrm{H} / \mathrm{He}$ mice. Behav Pharmacol 10: 7383.

Lewy AJ, Sack RL, Miller LS, Hoban TM (1987). Antidepressant and circadian phase-shifting effects of light. Science 235: 352 354.

Martinet L, Guardiola-Lemaître B, Mocaër E (1996). Entrainment of circadian rhythms by $S 20098$ a melatonin agonist is dose and plasma concentration dependent. Pharmacol Biochem Behav 54: 713-718.

Montgomery S (1980). Maprotiline, nomifensine, mianserin, zimelidine: a review of antidepressant efficacy in in-patients. Neuropharmacology 19: 1185-1190.

Moreau J-L, Scherschlict R, Jenck F, Martin JR (1995). Chronic mild stress-induced anhedonia model of depression: sleep abnormalities and curative effects of electroshock treatment. Behav Pharmacol 6: 682-687.

Muscat R, Papp M, Willner P (1992). Reversal of stress-induced anhedonia by the atypical antidepressants, fluoxetine and maprotiline. Psychopharmacology 109: 433-438.

Overstreet DH, Pucilowski O, Retton MC, Delagrange P, GuardiolaLemaitre B (1998). Effect of melatonin receptor ligands on swim test immobility. Neuroreport 9: 249-253.

Papp M, Sánchez C (2002). Escitalopram has potent and rapid effect in a chronic mild stress model of depression in rats. Biol Psychiatry 51: 68S.

Raghavendra V, Kaur G, Kulkarni SK (2000). Antidepressant action of melatonin in chronic forced swimming-induced behavioral despair in mice, role of peripheral benzodiazepine receptor modulation. Eur Neuropsychopharmacol 10: 473-481.

Redman JR, Francis AJP (1998). Entrainment of rat circadian rhythms by the melatonin agonist S-20098 requires intact suprachiasmatic nuclei but not the pineal. J Biol Rhythms 13: 39-51.

Redman JR, Guardiola-Lemaître B, Brown M, Delagrange P, Armstrong SM (1995). Dose-dependent effects of S 20098, a melatonin agonist on direction of reentrainment of rat circadian rhythms. Psychopharmacology 118: 385-390.

Rubin RT, Heist EK, McGeoy SS, Hanada K, Lesser IM (1992). Neuroendocrine aspects of primary endogenous depression. Arch Gen Psychiatry 49: 558-567.

Sack RL, Lewy AJ, White DM, Singer CM, Fireman MJ, Vandiver R (1990). Morning vs evening light therapy for winter depression: 
evidence that the therapeutic effects of light are mediated by circadian phase shifting. Arch Gen Psychiatry 47: 343-351.

Sanchez C, Hyttel J (1999). Comparison of the effects of antidepressants and their metabolites on reuptake of biogenic amines and on receptor binding. Cell Mol Neurobiol 19: $467-489$.

Sekula LK, Lucke JF, Heist EK, Czmbel RK, Rubin RT (1997). Neuroendocrine aspects of primary endogenous depression. Psychiatr Res 24: 143-153.

Shaji AV, Kulkarni SK (1998). Central nervous system depressant activities of melatonin in rats and mice. Ind J Exp Biol 36: 257263.

Souetre E, Salvati E, Belugou JL, Candito M, Krebs B, Ardisson JL et al (1989). Circadian rhythms in depression and recovery: evidence for blunted amplitude as the main chronobiological abnormality. Psychiatr Res 28: 263-278.

Strauss WH, Klieser E (1991). Psychotropic effects of ritanserin, a selective S2 antagonist: an open study. Eur Neuropsychopharmacol 1: 101-105.

Szymanska A, Rabe-Jablonska J, Karasek M (2001). Diurnal profile of melatonin concentrations in patients with major depression: relationship to the clinical manifestation and antidepressant treatment. Neuroendocrinol Lett 22: 192-198.

Thompson C, Franey C, Arendt J, Checkley SA (1988). A comparison of melatonin secretion in depressed patients and normal subjects. Br J Psychiatry 152: 260-265.

Van Reeth O, Olivares Y, Zhang FW, Turek FW, Defrance R, Mocaer E (1997). Comparative effects of a melatonin agonist on the circadian system in mice and syrian hamsters. Brain Res 762 : 185-194.
Van Reeth O, Weibel L, Olivares E, Maccari S, Mocaër E, Turek FW (2001). Melatonin or a melatonin agonist correct age-related changes in circadian response to an environmental stimulus. $\mathrm{Am}$ J Physiol 280: 1582-1591.

Wehr TA, Wirz-Justice A (1982). Circadian rhythm mechanisms in affective illness and in antidepressant drug action. Pharmacopsychiatry 15: 31-39.

Weibel L, Turek FW, Mocaër E, Van Reeth O (2000). A melatonin agonist facilitates circadian clock resynchronization in old hamsters after abrupt shifts in the light-dark cycle. Brain Res 880: 207-211.

Weibel L, Rettori MC, Lesieur D, Delagrange P, Renard P, Van Reeth O (1999). A single oral dose of S 22153, a melatonin antagonist, blocks the phase advancing effects of melatonin in C3H mice. Brain Res 829: 160-166.

Willner P (1997). Validity, reliability and utility of the chronic mild stress model of depression: a 10 years review and evaluation. Psychopharmacology 134: 319-329.

Ying SW, Rusak B, Delagrange P, Mocaër E, Renard P, GuardiolaLemaître B (1996). Melatonin analogues as agonist and antagonists in the circadian system and other brain areas. Eur J Pharmacol 296: 33-42.

Ying SW, Rusak B, Mocaer E (1998). Chronic exposure to melatonin receptor agonists does not alter their effects on suprachiasmatic nucleus neurons. Eur J Pharmacol 342: 29-37.

Yous S, Andrieux J, Howell HE, Morgan PJ, Renard P, Pfeiffer B et al (1992). Novel naphthalenic ligands with high affinity for the melatonin receptor. J Med Chem 35: 1484-1486.

Zetin M, Potkin S, Urbanchek M (1987). Melatonin in depression. Psychiatr Ann 17: 676-681. 